\title{
Assessing Teacher Dispositions In Pre-Service Teachers
}

Heidi Frederiksen, Ph.D., Colorado State University, Fort Collins, USA

Donna Cooner, Ph.D., Colorado State University, Fort Collins, USA

Cerissa Stevenson, Ph.D., Colorado State University, Fort Collins, USA

\begin{abstract}
The purpose of this study was to determine whether there was a significant difference between the perceived dispositions in pre-service teachers in urban settings versus non-urban settings. It was also the intent of this study to describe the change in perceived dispositions throughout preservice teachers' internship experiences. Graduate students $(N=44)$ from a teacher education program participated by providing responses to surveys, reflections, and focus groups. Final Assessment (FA) grades were also gathered to validate responses. The nature of self-reported data requires this study to collect both quantitative and qualitative data so that pre-service teachers' responses can be validated with their experience, which influenced the decision to employ a mixed-methods design for this study. A triangulation mixed methods design (QUANT + QUAL) was used. The quantitative analysis used a non-experimental comparative approach. Inductive within deductive coding was used to analyze the journal responses and focus groups. Template analysis (King, 2004) used pre-established codes based on the 10 INTASC Principles and Dispositions Indicators (1992). Themes also emerged inductively and were identified throughout the coding process.
\end{abstract}

Keywords: Teacher Preparation; Schools; Dispositions; Setting; Pre-Service Teachers

\section{INTRODUCTION}

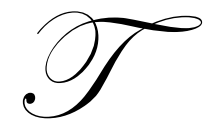

he recent focus on enhancing academic achievement for disadvantaged children has raised concerns about the lack of teacher quality in low-socioeconomic areas and high-minority schools. Sanders and Rivers indicate there is now evidence that "teacher quality is the single most accurate indicator of a student's performance in school" (1996, p. 6). As a result, the growing population of diverse students in our schools requires us to consider how we will help students to be successful. In order to accomplish this, it is up to teacher education programs to train the best teachers, and in doing so, they must identify program components that affect candidates' "perceptions, beliefs, and dispositions" that enable them to work effectively with the diverse students and families that crowd the halls of our urban schools today (Talbert-Johnson, 2006). This requires assessment of not only the knowledge and pedagogical skills of teacher candidates but also teacher dispositions: the values, commitments, and professional ethics that influence a teacher's behavior toward the school community. In 2000, Taylor and Wasicsko (as cited in Thompson, Ransdell, \& Rousseau, 2005, p. 23) concluded that "there is a relationship between teacher effectiveness and the dispositions of teachers." The current focus on teacher quality encourages teacher educators to delve deeper than ever before into which dispositions must be developed to create quality teachers who are prepared to teach in any setting.

\subsection{Research Problem}

Peske and Haycock gathered data about the distribution of teachers in Cleveland, Chicago and Milwaukee and found large differences between the number of qualified teachers in the highest poverty and highest minority schools than those schools with few minority or low-income students $(2006, \mathrm{p} .1)$. The reality is that change in the school system in the United States will never transpire if teacher education programs cannot adequately prepare teachers (Talbert-Johnson, 2006). 
Other researchers have shown there is a relationship between quality teachers and their dispositions: "Students learn more from teachers with certain characteristics" (Wayne \& Youngs, 2003). In addition, the internship experience in which pre-service teachers participate is an important aspect in improving the preparation of quality teachers. Past studies have shown that the quality of teachers increases when candidates are given more time in internship experiences. Singh says, "Field experiences... allow teacher candidates to apply and reflect on their content, professional, and pedagogical knowledge, skills as well as dispositions, in a variety of settings" (2006, p. 3).

\subsection{Research Questions}

Researchers in education have linked teacher dispositions to teacher quality (McKay, 1997; Sachs, 2004; Sharp, 2008; Talbert-Johnson, 2006; Taylor \& Wasicsko, 2000; Thompson, et al., 2005; Wayne \& Youngs, 2003), yet a thorough investigation of literature found no empirical studies linking how pre-service teacher dispositions were affected by internship experience, meaning the length of the experience, or setting.

To study how dispositions develop in pre-service teachers, this research focused on the experience and setting (urban or non-urban). By focusing on the experiences in which a pre-service teacher participates, a clearer understanding of how perceived dispositions might change from the practicum through the student-teaching experience could be gained. The focus on setting helped to determine whether different perceived dispositions were displayed in one setting (urban) versus the other (non-urban). The following questions were asked:

1. Does experience validate perception of dispositions?

a. Do perceptions of dispositions change as a candidate gains experience in the classroom?

b. What perceived dispositions are stronger/weaker at the beginning of the candidate's internship experience than at the end of the internship experience?

2. Does setting validate perception of dispositions?

a. Does the setting (urban vs. non-urban) influence the strength of the dispositions?

b. Does the setting influence the "professional rating" of a pre-service teacher?

\section{METHODOLOGY}

\subsection{Participants}

Candidates from the one-year master's plus teaching license program (Option \#3) at Colorado State University were included in the study. Only those who attended during the 2009-2010 academic year participated. During the data gathering process, teacher licensure candidates participated in a practicum and seminar during the fall semester, and student teaching and another seminar during the spring semester. Thus, in this study, the setting refers to the location where the student teaching experience occurred (urban or non-urban), while instructional setting refers to the setting in which students participated in courses (urban high school, non-urban high school).

The entire available sample was used, which consisted of two cohorts with a total of 44 students; 16 males and 28 females. In addition, 16 pre-service teachers participated in the urban instructional setting, while 28 participated in the non-urban instructional setting. It is not considered to be the entire population because similar programs exist and the study could easily be replicated in other locations.

\subsection{Measures}

The Teacher Disposition Index (TDI) was used for this study. The instrument was analyzed for reliability and validity (Schulte, Edick, Edwards, \& Mackiel, 2004). Schulte, et al. claim: "The item development phase and the content validity procedures ensured that the TDI measured the dispositions of effective teachers as specified in the INTASC (1991) Principles" (2004). The researchers/developers of the TDI wanted to investigate common variance in order to determine the number of dimensions that the TDI measured. Investigators reported that the TDI measured two constructs: a "Student-Centered" dimension and a "Professionalism, Curriculum-Centered" dimension. Reliability for the TDI subscales was measured using Chronbach's alpha (Schulte, et al., 2004). 
Qualitative analysis was validated from several sources from several individuals through the triangulation process which is advantageous "because it...can result in well-validated and substantiated findings" (Creswell \& Plano-Clark, 2007). Responses were coded with the 10 INTASC Principles and analyzed by using inductive within deductive coding.

Data from students' Final Assessment (FA) collected by CSU's School of Teacher Education and Principal Preparation (STEPP) was also used for validation. The FA score is a composite score rating the professionalism of the pre-service teacher during the internship experience. It is determined by both the cooperating teacher and the university supervisor and was collected at the end of the internship experience. Another measure of validity was added at the end of the internship experience in terms of focus groups. These were conducted in groups of four students at a time according to instructional setting. Participants discussed specific questions about their experiences and the structure of the program. These groups were recorded, and then transcribed for coding.

\subsection{Procedure}

Participants (pre-service teachers) used the online blackboard program at CSU called RamCT (used by Colorado State University faculty and students for communication, collaboration and learning) to complete and submit their reflections and surveys. This program is easily accessible from any computer with online capabilities. Each member of the cohort was asked to complete seven open-ended questions designed for qualitative analysis. A Likert-type survey, the Teacher Disposition Index (TDI), was given to participants towards the end of each semester of practicum experience, also scaled and designed for quantitative analysis.

The first stage of the analysis represents students' responses to open-ended questions based on the ten INTASC Principles (the principles set forth by the Interstate New Teacher Assessment and Support Consortium in 1992 with the purpose of assessing pre-service teachers and programs of teacher education) gathered over fall and spring semesters. These were used in addition to participant responses from the TDI at the end. The open-ended questions and focus groups were designed to validate and explain data collected from the TDI. Demographic information such as content area and setting for internship was entered for each participant via the instrument. Participants submitted prompts bimonthly during the fall and spring semesters of the Option \#3 program. Spring semester also included collection of focus group responses and Final Assessment scores.

The next part of the analysis included the qualitative and quantitative analysis of data using NVivo and PASW8 using the 10 INTASC Principles and Dispositions Indicators. The last stage included mixing the qualitative results with the quantitative findings to find patterns and relationships in order to answer the research questions and provide recommendations based on the findings.

All information was given and stored electronically. Each individual student granted access to the data in this study. Responses were monitored for completion and included as a grade in the seminar, taken concurrently with participants' practicum experience. Data analysis began once the practicum student teaching was finished in the spring semester of 2010 .

\subsection{Analysis}

The objective of this study was to examine whether pre-service teachers' perceptions of dispositions are influenced by experience and setting. This analysis was based on the research questions:

1. Does experience validate perception of dispositions?

2. Does setting validate perception of dispositions?

\subsubsection{Quantitative Analysis}

The quantitative analysis utilized the PASW8 statistical analysis program and "SPSS for Introductory Statistics: Use and Interpretation" (Morgan, Leech, Gloeckner, \& Caplovitz-Barrett, 2007). Descriptive numerical and graphical analyses were initially examined to determine the appropriate test and post-hoc comparisons. It was 
assumed that there were no violations of normality or homogeneity of variance, so the following statistics were used:

1a. A paired t-test was used to measure the difference in student responses for individual questions on the TDI between fall and spring semester. In addition, questions were grouped by principle and compared using a paired t-test to compare change over time.

1b. Means were used to rank the 10 INTASC Principles for each semester.

2a. A one-way analysis of variance (ANOVA) was used to examine the strengths of perceived dispositions in urban versus non-urban settings.

2b. An independent samples t-test was used to determine if the setting (urban vs. non-urban) influences the 'professional rating' of a pre-service teacher. Principles were also grouped into "StudentCentered" and "Professionalism, Curriculum-Centered" categories according to the questions within the TDI, and used a one-way ANOVA to compare the difference in settings.

\subsubsection{Qualitative Analysis}

All responses were coded using the process of Template Analysis (King, 2004), where data was coded using the 10 INTASC Principles and Dispositions Indicators, then analyzed deductively within the two constructs, "Student-Centered" and "Professionalism, Curriculum-Centered." Narratives were then analyzed deductively.

\subsection{3 $\quad$ Mixed}

The main research questions, addressing the validation of perceptions of dispositions with experience and setting, used a three stage structure: Stage I was the qualitative Template Analysis including inductive within deductive coding. Stage II was the quantitative phase. Descriptive and inferential statistics were used to analyze quantitative data. In Stage III, qualitative and quantitative data were merged so that a complete picture was developed of how the two sets of data were related. Essentially, qualitative data were "quantized" so that data could be compared in a non-biased manner. The results of Stage III compared the "quantized" qualitative data with the quantitative data in discussion format.

A mixed study was conducted, because the purpose of this research was to investigate whether perceived dispositions in pre-service teachers were influenced by experience and setting (urban versus non-urban). The nature of self-reported data required this study to collect both quantitative and qualitative data so that pre-service teachers' responses could be validated with their experiences. This required the gathering of qualitative and quantitative data at the same time (Cresswell \& Plano-Clark, 2007). The assumption was that only by comparing data from different sources could we try to determine what a reliable basis for inference is.

In summary, the identified attribute independent variables were experience and setting. Experience refers to the internship experience (fall semester or spring semester). The second variable, setting, refers to the type of school in which a pre-service teacher experiences the student teaching internship (urban or non-urban) or the instructional setting in which focus group discussions were facilitated. The dependent variable is the pre-service teachers' perceptions of their own disposition. The FA score, calculated by the participants' cooperating teachers and university supervisors, also measured an outside perspective on dispositions of pre-service teachers. Paired ttest and one-way ANOVA procedures were used to analyze the quantitative research questions.

\section{RESULTS AND DISCUSSION}

With the changing face of K-12 schools in the United States, teacher quality has become the political and social focus for education. Research indicates that the correlation between teacher quality and student achievement is stronger than the one that exists between students' socio-economic status and other background characteristics, and their achievement (Weglinsky, 2002).

Research suggests teacher dispositions are important aspects of training and assessing quality teachers. Accrediting agencies for teacher education, such as INTASC, TEAC and NCATE, have taken the research seriously, requiring teachers to have the "knowledge, skills and dispositions" necessary to be effective. 
Internship experience has been found to be the most important aspect of teacher training (Doppen, 2007; McKinney et al., 2008; Ross, 1986; Singh, 2006), and a variety of settings have been identified to be an important factor in training quality teachers (Epstein, 2005; Epstein and Sanders, 2006; Hedges and Gibbs, 2005; HooverDempsey, Walker, Jones \& Reed, 2002; as cited in Curran \& Murray, 2008, p. 104). Although the components that could be considered are infinite, it was determined, for this study, to focus on how teacher dispositions are influenced by internship experience and setting.

Statistically significant differences were found for seven of the 45 questions included in the TDI, measured over time. In addition, seven of the ten INTASC Principles showed significant differences in change over time, specifically, Principles 4,7 , and 9 which were supported by narratives provided by participants in focus groups.

When compared in an independent samples t-test, no statistical significance existed between perceived dispositions in the urban setting versus the non-urban setting. However, when narratives were examined, some differences emerged between urban and non-urban settings. Urban settings tended to emphasize "Student-Centered" dispositions while non-urban students highlighted "Professional, Curriculum-Centered" dispositions.

\subsection{Does experience validate perception of dispositions?}

The perceived dispositions scores between pre-test and post-test on the TDI were examined using a paired samples t-test. Because of the small number of respondents taking the TDI both fall and spring semesters $(\mathrm{n}=7)$, normality was tested using differences between scores. Not all pairs were found to be normally distributed, so a Mann-Whitney test was performed. dispositions:

Below, Table 1 lists the questions in the survey reporting significant decrease in perceptions of

Table 1: Significant Decreases in Perceived Dispositions, Pre-Test to Post-Test (TDI)

\begin{tabular}{lccc}
\hline Question from TDI Survey & $\begin{array}{c}\text { INTASC } \\
\text { Principle } \\
\text { Represented }\end{array}$ & Significance & $\begin{array}{c}\text { Mean } \\
\text { Difference }\end{array}$ \\
\hline $\begin{array}{l}\text { 2. I understand that students learn in many } \\
\text { different ways. }\end{array}$ & 3 & 0.045 & 1.185 \\
$\begin{array}{l}\text { 3. I demonstrate qualities of humor, empathy, and } \\
\text { warmth with others. }\end{array}$ & 5 & 0.004 & 1.247 \\
$\begin{array}{l}\text { 6. I believe that all students can learn. } \\
\text { 23. I am open to adjusting and revising my plans to } \\
\text { meet student needs. }\end{array}$ & 2 & 0.004 & 1.692 \\
$\begin{array}{l}\text { 25. I believe it is important to learn about students } \\
\text { and their community. }\end{array}$ & 7 & 0.047 & 1.062 \\
$\begin{array}{l}\text { 31. I uphold the laws and ethical codes governing } \\
\text { the teaching profession. }\end{array}$ & 9 & 0.002 & 2.140 \\
\hline
\end{tabular}

Table 2, included below, lists the specific questions from the survey showing increased perceptions of dispositions:

Table 2: Significant Increases in Perceived Dispositions, Pre-Test to Post-Test (TDI)

\begin{tabular}{|c|c|c|c|c|}
\hline Question from TDI Survey & $\begin{array}{c}\text { INTASC } \\
\text { Principle } \\
\text { Represented }\end{array}$ & Significance & $d$ & $\begin{array}{c}\text { Mean } \\
\text { Difference }\end{array}$ \\
\hline $\begin{array}{l}\text { 21. I am willing to receive feedback and } \\
\text { assessment of my teaching. }\end{array}$ & 9 & 0.011 & 2.138 & 1.71 \\
\hline $\begin{array}{l}\text { 29. I cooperate with colleagues in planning } \\
\text { instruction. }\end{array}$ & 7 & 0.047 & 1.446 & 1.43 \\
\hline $\begin{array}{l}\text { 45. I take initiative to promote ethical and } \\
\text { responsible professional practice. }\end{array}$ & 9 & $<.001$ & 8.596 & 7.14 \\
\hline
\end{tabular}


Out of the 10 INTASC Principles, seven were found to show significant differences from post-test to pretest. In addition, all but Principle 4 were found to have larger than typical effect sizes. Principle 4 does show a medium to large effect size. Below, Table 3 reports significant principles:

Table 3: Significant Differences in INTASC Principles, Post-Test to Pre-Test (TDI)

\begin{tabular}{lcccc}
\multicolumn{1}{c}{ INTASC Principle } & Significance & $\boldsymbol{d}$ & $\begin{array}{c}\text { Mean } \\
\text { Difference }\end{array}$ & $\begin{array}{c}\text { Increase or } \\
\text { Decrease }\end{array}$ \\
\hline Principle 1: Making Content Meaningful & 0.006 & -3.63 & -1.57 & Decrease \\
Principle 4: Instructional Strategies and Problem Solving & 0.007 & 0.75 & 0.81 & Increase \\
Principle 5: Motivation and Behavior & 0.002 & -1.32 & -0.75 & Decrease \\
Principle 7: Planning for Instruction & 0.004 & -1.66 & -0.82 & Decrease \\
Principle 8: Assessment & 0.003 & 2.81 & 2.57 & Increase \\
Principle 9: Professional Growth and Reflection & 0.001 & -2.16 & -0.98 & Decrease \\
Principle 10: Interpersonal Relationships & 0.033 & -1.73 & -1.33 & Decrease \\
\hline
\end{tabular}

Eleven focus group discussions were conducted; four were instructed in an urban setting, while seven were instructed in a non-urban setting. Participants responded to the question: In what area do you believe you grew the most?

INTASC Principle 4: Instructional Strategies and Problem Solving was the most frequent principle discussed in focus groups. Many participants highlighted instructional strategies such as differentiation, organization and writing effective lessons, as reflected in participant responses:

[I learned about] student centered learning and making sure that students have that power in their education. That they learn better that way.

I learned that I had to teach in steps and really read how my students were doing.

Learning how integrated everything is...classroom management, differentiation, instructional strategies. It all makes up the classroom. You need all of it to be successful.

I really came to understand and appreciate that lesson planning strategy. And to justify the things I did with my students.

Another area of growth mentioned was Principle 5: Motivation and Behavior. Participants' responses touched on issues of expectations of students and classroom management:

They were more raw than I expected them to be. I didn't expect to hear them cussing and absolutely refuse to do anything.

I never thought I'd have to teach children the skills of school. What it means to be responsible for bringing your pencil and having your materials. At the same time, understanding that some kids don't have their pencil and materials for a reason. It's an eloquent balance that needs to happen every day, every minute.

I have become more forceful though, when it came time to buckle down and get something done.

...It became more natural to address problems. I'm more direct with them now. You have to be.

The final area of growth mentioned in the top three Principles was Principle 9: Professional Growth and Reflection. Comments made by participants emphasized topics such as increased confidence, learning from experience, collaboration with others, and the importance of a teacher's responsibility: 
If I was just to go into student teaching without ever having been in a classroom, I wouldn't have grown as much.

My confidence has grown 20-fold since I started.

Ifelt like I had a team behind me - it gave me a lot of strength.

I have come so far and actually felt comfortable student teaching. I'm way more confident that I was before.

\subsection{Do perceptions of dispositions change as a candidate gains experience in the classroom?}

The questions from the TDI were categorized by INTASC principle. Means were calculated for each Principle and the dispositions were listed in order from strongest to weakest. See Table 4, included below, for results:

Table 4: Ranking of INTASC Principles for Each Semester by Mean Response

\begin{tabular}{|c|c|c|c|c|}
\hline Rank & Fall Semester & Mean & Spring Semester & Mean \\
\hline 1 & $\begin{array}{l}\text { Principle 9: } \\
\text { Professional Growth/Reflection }\end{array}$ & 9.14 & $\begin{array}{l}\text { Principle 3: } \\
\text { Learning Styles and Diversity }\end{array}$ & 9.11 \\
\hline 2 & $\begin{array}{l}\text { Principle 2: } \\
\text { Child Development and Learning Theory }\end{array}$ & 9.04 & $\begin{array}{l}\text { Principle 2: } \\
\text { Child Development and Learning Theory }\end{array}$ & 8.81 \\
\hline 3 & $\begin{array}{l}\text { Principle 5: } \\
\text { Motivation and Behavior }\end{array}$ & 8.85 & $\begin{array}{l}\text { Principle 6: } \\
\text { Communication and Knowledge }\end{array}$ & 8.78 \\
\hline 4 & $\begin{array}{l}\text { Principle } 7 \text { : } \\
\text { Planning for Instruction }\end{array}$ & 8.85 & $\begin{array}{l}\text { Principle 5: } \\
\text { Motivation and Behavior }\end{array}$ & 8.63 \\
\hline 5 & $\begin{array}{l}\text { Principle 3: } \\
\text { Learning Styles/Diversity }\end{array}$ & 8.80 & $\begin{array}{l}\text { Principle 9: } \\
\text { Professional Growth and Reflection }\end{array}$ & 8.38 \\
\hline 6 & $\begin{array}{l}\text { Principle 1: } \\
\text { Making Content Meaningful }\end{array}$ & 8.72 & $\begin{array}{l}\text { Principle 7: } \\
\text { Planning for Instruction }\end{array}$ & 8.27 \\
\hline 7 & $\begin{array}{l}\text { Principle 6: } \\
\text { Communication/Knowledge }\end{array}$ & 8.24 & $\begin{array}{l}\text { Principle 4: } \\
\text { Instructional Strategies and Problem Solving }\end{array}$ & 8.09 \\
\hline 8 & $\begin{array}{l}\text { Principle 10: } \\
\text { Interpersonal Relationships }\end{array}$ & 7.53 & $\begin{array}{l}\text { Principle 8: } \\
\text { Assessment }\end{array}$ & 7.96 \\
\hline 9 & $\begin{array}{l}\text { Principle 4: } \\
\text { Instructional Strategies/Problem Solving }\end{array}$ & 6.85 & $\begin{array}{l}\text { Principle 1: } \\
\text { Making Content Meaningful }\end{array}$ & 7.32 \\
\hline 10 & $\begin{array}{l}\text { Principle 8: } \\
\text { Assessment }\end{array}$ & 5.70 & $\begin{array}{l}\text { Principle 10: } \\
\text { Interpersonal Relationships }\end{array}$ & 6.87 \\
\hline
\end{tabular}

The qualitative analysis included 39 participants. Reflection responses were coded inductively within each INTASC Principle. The following table (Table 5) lists the 10 Principles for each semester, ranked in order of frequency of participants responding (out of 39).

Table 5: Reflection Responses Ranked by INTASC Principle According to Frequency for Each Semester

\begin{tabular}{lcll}
\hline Fall Semester & & Spring Semester & Frequency \\
\hline Principle & Frequency & Principle & 34 \\
4: Instructional Strategies and Problem Solving & 30 & 5: Motivation and Behavior & 33 \\
5: Motivation and Behavior & 28 & $3:$ Learning Styles and Diversity & 33 \\
10: Interpersonal Relationships & 28 & $4:$ Instructional Strategies and Problem Solving \\
1: Making Content Meaningful & 20 & $1:$ Making Content Meaningful & 32 \\
7: Planning for Instruction & 19 & $10:$ Interpersonal Relationships & 30 \\
2: Child Development and Learning Theory & 16 & $2:$ Child Development and Learning Theory \\
3: Learning Styles/Diversity & 16 & $7:$ Planning for Instruction & 24 \\
8: Assessment & 9 & $9:$ Professional Growth and Reflection & 19 \\
6: Communication and Knowledge & 4 & $8:$ Assessment & 7 \\
9: Professional Growth and Reflection & 2 & 6: Communication and Knowledge & 2 \\
\hline
\end{tabular}


Notable positive changes occurred in INTASC Principles 5 and 3 during students' internship experiences. Negative changes were noted in Principles 4, 10 and 7.

INTASC Principle 5: Motivation and Behavior was the most mentioned during the spring semester. Preservice teachers commented on the importance of a positive classroom environment, managing difficult students, cooperative learning, and motivating students in their classrooms:

Nipping unacceptable speech in the bud early can help prevent a long-term pattern of negative behavior.

We agreed that building a support network for the students in the school environment and helping students gain control in school was key to helping them turn things around.

He was still apathetic until I started pointing out activities and topics that I have heard him mention throughout the semester. This tactic finally worked and on the last speech this student used inflection, was prepared, smiled and spoke with enthusiasm!!!!!!

By establishing a relationship and getting to know him I have opened him up and made him more receptive to my teaching, I will continue to establish more trust and work to make the content more relevant to him by making connections to things he is interested in.

Having the students in groups allows for many peer to peer teaching moments and provides opportunities for students who normally struggle with writing a chance to be successful.

The second Principle to increase in ranking is Principle 3: Learning Styles and Diversity:

Being in a poor community opens your eyes to a wide-range of different personalities.

I guess it is the unique students I will never forget.

Find the story and you can understand them better, thus learning can occur.

...We are constantly questioning what interventions/accommodations would best suit our most troubled students.

INTASC Principles 4, 10 and 7 showed a decrease in responses from fall semester to spring semester. Of those three, pre-service teachers had many negative responses relating to Principle 4: Instructional Strategies. Participants commented about critical thinking in the classroom and making content relevant to learners:

Some will even refuse to write down their ideas and would rather forfeit the question than try.

As teachers at this institution we are also encouraged to hold students hands on many tasks and this will and does inhibit their critical thinking skills.

...For the most part, that the students here are not thinking outside the box or beyond what is asked, or go beyond when asked.

\subsection{Does the setting (urban vs. non-urban) influence the strength of the dispositions?}

The two settings (urban and non-urban) were compared to the 10 INTASC Principles using a one-way analysis of variance (ANOVA). The assumption of homogeneity of variance was violated in Principles 1, 4, and 10; therefore, the Welch F-Ratio was reported. There were no significant statistical differences for any principle between settings.

Qualitative data between the two groups, urban and non-urban, include 18 participants who did their student teaching in an urban setting, and 16 in a non-urban setting. In addition, seven focus groups were instructed 
in a non-urban setting and four in an urban setting. Because these numbers are not equal, qualitative data will be reported in percentages (number of responses per total responses in that setting).

When setting was compared to the INTASC Principles, only Principles 2 and 3 showed major differences. All other principles had similar percentages coming from each setting. Principle 2: Child development and Learning Theory included $9.4 \%$ of respondents from an urban setting and $6.6 \%$ from a non-urban setting. Principle 3: Learning Styles and Diversity included $11.9 \%$ of respondents from an urban setting and $8.7 \%$ from a non-urban setting. Because differences were not significant, narratives were not further examined for themes. It was found that $70 \%$ of negative responses came from participants interning in an urban setting. Participants in urban student teaching settings who commented negatively highlighted student motivation and behavior as a concern:

I know that he doesn't care about school or passing, so I just try to be a positive adult figure in his life, just in case he ever decides to shape up and get serious about his academic career.

At first, when I tried to talk to him, he didn't want to engage in conversation. So I tried different things such as moving his seat, timing him out when he disturbed class, and giving him modified assignments because I thought he didn't understand the material. None of that seemed to work...

Non-urban participants commented on critical thinking skills in students as a concern:

...When I ask students to fill a graduated cylinder to a certain amount and they ask me 4 times how to do this I am not overly optimistic of their critical thinking abilities.

\subsection{Does the setting influence the "professional rating" of a pre-service teacher?}

Final Assessment (FA) data was a culminating grade given to participants at the end of their student teaching experiences. This grade was given by the university supervisor and cooperating teacher and represents the "Professional Rating" of a teacher candidate. No significant difference was found between the two settings related to the FA score.

Further investigation was conducted by combining individual responses from the TDI to form the subscales "Student-Centered" and "Professionalism, Curriculum-Centered." There were no significant differences for either one of the subscales when compared to setting.

\subsection{Mixed Results}

\subsubsection{Does experience validate perception of dispositions?}

Seven of the ten INTASC Principles showed a significant change over time. Narratives provided by the participants supported these findings, especially for Principles 4, 7, and 9. Though Principle 3 showed no significant difference in the quantitative analysis, significance is supported by the narratives provided and qualitative rankings.

Principle 4: Instructional Strategies and Problem Solving, showed a significant increase when analyzed from fall to spring. However, $70 \%$ of the negative responses provided by participants were linked to this principle.

Another INTASC Principle that increased in significance is Principle 9: Professional Growth and Reflection. Not only did two of the significant questions posed to participants represent that principle, it was also supported by their narratives, ranking in the top three most cited principles by focus groups and increasing by two ranks when compared from fall to spring semester.

The principle showing significant decrease in both quantitative and qualitative analysis was Principle 7: Planning for Instruction. It was among the statistically significant standards and is represented by two significantly decreasing questions from the TDI. In addition, Principle 7 decreased by two in ranking in both the quantitative and qualitative analysis. It was also a Principle that included negative responses. 
Although not statistically significant, Principle 3, Learning Styles and Diversity, should be mentioned as practically significant, as supported by ranking in both quantitative and qualitative analysis. It ranked number one overall in the spring semester when means were compared, increasing in rank by four. In addition, it increased in rank by 5 in the qualitative responses, ranking number two overall for spring semester.

\subsubsection{Does setting validate perception of dispositions?}

Quantitative analysis revealed no statistical significance in perceived dispositions by setting (urban or nonurban) or differences in Final Assessment scores by setting. However, narrative results indicate practical differences in dispositions between the two settings. When the groups were compared by percentage of responses coded within each standard, differences were noted in Principle 2: Child Development and Learning Theory, and Principle 3: Learning Styles and Diversity, with the urban group having a higher percentage of responses in both cases. Principles 5: Motivation and Behavior and Principle 2: Child Development and Learning Theory were also in the top three ranked for the urban focus groups. The non-urban focus groups included Principles 3: Learning Styles and Diversity and Principle 4: Instructional Strategies and Problem Solving as the top three principles cited. There was a similarity in dispositions between urban and non-urban settings. Both groups ranked Principle 10: Interpersonal Relationships as second in focus group discussion responses.

Adding narrative responses allows for a detailed understanding of the research. "Professional Rating" could not be analyzed qualitatively in an effective way because of the nature of the questioning. However, if the qualitative differences between the two settings were categorized according to the TDI subscales, a difference can be seen between the "Student-Centered" dispositions and the "Professional, Curriculum-Centered" dispositions. Specifically, the ranked principles for the urban focus groups included Motivation and Behavior and Child Development and Learning Theory, which are both included in the "Student-Centered" subscale. The "Professional, Curriculum Centered" subscale included Learning Styles and Diversity and Instructional Strategies and Problem Solving, which were in the top three ranked principles in the non-urban focus groups.

As such, this study shows that, of the ten INTASC Principles, seven were found to change significantly over time. This supports the research by Castle, et al. (2006) concluding that a developmental continuum exists for pre-service teachers. Castle contends that beginning teachers concentrate on their own performance at first, then, with experience, shift to concentrating on student performance, which may explain the changes in specific principles (both increasing and decreasing). Specific positive changes related to this idea were found in Principles 3: Learning Styles and Diversity and 4: Instructional Strategies and Problem Solving. This idea may also account for the decrease in Principle 9: Professional Growth and Reflection.

When perceptions of dispositions were analyzed between urban and non-urban groups, one important similarity was found: Principle 10: Interpersonal Relationships. This finding is supported by researchers Perez (2009) and Wentzel (1992). Both contend that caring relationships with teachers helped students to be motivated because they provided both social and emotional growth. Narratives from participants in this study focus on the importance of building relationships to improve student motivation and classroom management.

Findings in the synthesis were that dispositions found to be effective in urban settings were "StudentCentered", while effective dispositions in non-urban settings focused on the "Professionalism, CurriculumCentered" aspects of teaching. When the groups were compared by percentage of responses coded within each standard, differences were noted in Principle 2: Child Development and Learning Theory, and Principle 3: Learning Styles and Diversity, with the urban group having a higher percentage of responses in both cases. Principles 5: Motivation and Behavior and Principle 2: Child Development and Learning Theory were also in the top three ranked for the urban focus groups. The non-urban focus groups included Principles 3: Learning Styles and Diversity and Principle 4: Instructional Strategies and Problem Solving as the top three principles cited. Because creators of the TDI categorized the INTASC Principles into subscales called "Student-Centered" and "Professionalism, Curriculum-Centered," when placed into these two categories, urban strengths are included in the "StudentCentered" subscale and non-urban strengths are included in the "Professionalism, Curriculum-Centered" subscale. 
Reynolds, Ross and Rakow recognized that pre-service teachers in a PDS (professional development school) were more confident and, because of the longer placement in a PDS, were more engaged in their selfreflection (2003). This research supports the findings in this study, for while Principle 9: Professional Growth and Reflection did not show a significant change when analyzed quantitatively, it was found to have major changes when narratives were analyzed.

\section{GENERAL DISCUSSION}

\subsection{Conclusions}

The emphasis on producing quality teachers has gained the attention of accrediting agencies and programs of teacher education alike. Empirical evaluation of program components is necessary to gain insight into how to prepare teachers to be successful in any setting. Researchers such as Talbert-Johnson (2006) and Wayne et al. (2003) contend that there is a relationship between the quality of a teacher and dispositions.

The findings of this study support changes in dispositions over time spent in the internship, with seven out of ten INTASC Principles showing significant change over time. This evidence attests that dispositions can and do change when pre-service teachers are given authentic experiences in the classroom.

Curran and Murray (2008) say that adding "carefully constructed challenges" can develop dispositions in pre-service teachers. In addition, Parkinson's (2008) research connects theory and practice by providing "systematic and intentional" field experiences. Thoughtful planning of pre-service teachers' experiences, such as internships, within teacher education programs can help in developing desireable dispositions.

Narratives from participants do show differences between the groups, not only in the number of responses per principle, but also in content of the responses. No empirical studies could be found comparing urban teaching to non-urban teaching related to dispositions, but a synthesis of research indicates that the difference may be in the type of dispositions displayed by the teacher. Findings support this idea, with participants both in the urban setting for internship and for instructional groups perceiving stronger dispositions to be "Student-Centered." The non-urban group perceived stronger dispositions in the "Professionalism, Curriculum-Centered" realm. This study suggests that successful teachers who work with diverse populations require more "Student-Centered" dispositions to be successful, while non-urban teachers require more "Professionalism, Curriculum-Centered" dispositions. Non-urban participants included the following as areas of growth: instructional strategies such as chunking instruction, collaborative learning, and clear directions, communication with parents, writing objectives based on standards and being flexible in their planning, and goal-setting and results driven instruction.

These results can inform programs of teacher education as to how to prepare teachers to work in any setting. Talbert-Johnson (2006) contends that dispositions can be developed by deliberately planning and assessing throughout the teacher preparation program. Thoughtfully planning experiences and instruction based on what works for all students could help to prepare teachers to be successful in any setting.

As such, this study has the potential to contribute to the understanding of the development of desirable dispositions in pre-service teachers. Creating internship experiences that are challenging and thoughtful, as well as integrating interns in authentic settings, will help to develop desirable dispositions. Principles that were not developed as well as others in this study (Principles 6: Communication and Knowledge, 8: Assessment and 9: Professional Growth and Reflection) could be strengthened by creating experiences that force pre-service teachers to develop the desired disposition.

\subsection{Recommendations}

Additional inquiry into the development of desired dispositions is necessary in order to generalize these results. This study is delimited to one university and a low response rate for the qualitative analysis. The components of teacher preparation considered in this study were the assessment of teacher dispositions as related to setting and internship experience, and including final portfolios and a more in-depth analysis of outside evaluation 
might give more insight on the development of dispositions as well as increasing the confidence of the results. In addition, other factors, such as content area and level of teaching (elementary, middle, or high school), were not considered. It would be of notable interest to determine what dispositions should be developed to be successful in those areas. It is also necessary that researchers continue to study the assessment of dispositions and work to find a common definition and approach to implementation.

Lastly, the emphasis on building $21^{\text {st }}$ century skills in our students may be an important factor in developing dispositions in teachers. Common $21^{\text {st }}$ century themes throughout the new standards include collaboration, critical thinking, and technology. The INTASC research-based document still has ten standards, but two have changed to focus more on the learner. The ten standards have also been put into four categories: The Learner and Learning, Content Knowledge, Instructional Practice, and Professional Responsibility. Research using the new INTASC standards is imperative as $21^{\text {st }}$ century skills are emphasized in today's classrooms.

In summary, the results of this research lead to three recommendations for teacher educators:

1.) The development of "Student-Centered" dispositions in urban settings and "Professionalism, CurriculumCentered" dispositions in non-urban settings calls for internship and student-teaching placements to be held in a variety of settings so that the full menu of dispositions can be developed.

2.) Dispositions can be developed over time. Providing several experiences throughout a pre-service teacher's program will help them to develop desired dispositions.

3.) In order to develop the desired positive dispositions in teacher candidates, a variety of experiences and scenarios should be intentionally provided so that candidates are educated about the realities of teaching.

Still, further analysis of the assessment of dispositions in pre-service teachers is necessary. Specific programmatic components were studied, but there are many more to analyze. Also, new findings can support the changes in teacher preparation based on the necessary skills for developing $21^{\text {st }}$ century learners. This study revealed the value of having authentic internship experiences, including time in the classroom and appropriate settings to develop desired dispositions. Continuing study of pre-service teachers in various instructional and internship settings could strengthen the result of this inquiry. Replicating this study at other institutions and using the same instrument would also enable results to be generalized. Additional analysis using portfolios, outside observations, and the new INTASC standards is also imperative. In this time of change, teacher educators must evaluate and improve programs to ensure that quality teachers emerge who are able to help all students succeed. As student demographics continue to change and teaching increases in complexity, it is important to define the performances, essential knowledge, and critical dispositions needed by all teachers to help all students be successful.

\section{AUTHOR INFORMATION}

Dr. Heidi Frederiksen is a key advisor and coordinator of the principal licensure program in the School of Teacher Education and Principal Preparation at Colorado State University. Her research interests include teacher preparation and dispositions. E-mail: heidi.frederiksen@ colostate.edu

Dr. Donna Cooner is an associate professor at Colorado State University and program chair for graduate work in Educational Leadership. Her research interests include work in professional development schools, new teacher and principal induction, and program evaluation. She is also an author of Becoming a Teacher in a Field-Based Setting. E-mail: donna.cooner_gines@ colostate.edu. Corresponding author.

Dr. Cerissa Stevenson is an assistant professor in the School of Teacher Education and Principal Preparation at Colorado State University. She is the Early Childhood Education Coordinator and her research interests include teacher and principal preparation. E-mail: cerissa.stevenson@colostate.edu 


\section{REFERENCES}

1. Creswell, J. W., \& Plano-Clark, V. L. (2007). Designing and Conducting Mixed Methods Research. Thousand Oaks: Sage Publications, Inc.

2. $\quad$ Creswell, J. W. (2009). Research Design: qualitative, quanititative, and mixed methods approaches. Thousand Oaks: SAGE Publications, Inc.

3. Cruickshank, D. (1981). What we know about teachers' problems. Educational Leadership , 402-405.

4. Curran, E., \& Murray, M. (2008). Transforming learning in teacher education: beuilding competencies and changing dispositions. Journal of the Scholarship of Teaching and Learning, 103-118.

5. Doppen, F. (2007). The influence of a teacher preparation program on preservice social studies teachers' beliefs: A case study. Journal of Social Studies Research , 54-63.

6. Epstein, J. (2005). Links in a professional development chain: Preservice and inservice education for effective programs of school, family, and community partnerships. The New Educator, 124-141.

7. Epstein, J., \& Sanders, M. (2006). Prospects for change: Preparing educators for school, family, and community partnerships. Peabody Journal of Education, 81-120.

8. Hedges, H., \& Gibbs, C. (2005). Preparation for teacher-parent partnerships: A practical experience with a family. Journal of Early Childhood Teacher Education , 115-126.

9. Hoover-Dempsey, K., Walker, J., Jones, K., \& Reed, R. (2002). Teachers involving parents (TIP): Results of an in-service teacher education program for enhancing parental involvement. Teaching and Teacher Education , 843-867.

10. InTASC. (2010, July). Model Core Teaching Standards:A Model for Dialogue. Retrieved August 2010, from Council of Chief State School Officers:

http://beta.ccsso.org/Documents/2010/Model_Core_Teaching_Standards_DRAFT_FOR_PUBLIC_COMM ENT_2010.pdf

11. INTASC Standards. (1992). Retrieved April 17, 2010, from Council of Chief State School Officers: http://www.ccsso.org/content/pdfs/corestrd.pdf

12. King, N. (2004). Using templates in the thematic analysis of text. In C. Cassell, \& G. Symon, Guide to Qualitative Methods in Organizational REsearch. London: Sage.

13. McKay, J. (1997). Examining the elusive essence of a superlative teacher. Education, 433-439.

14. McKinney, S. E., Haberman, M., Stafford-Johnson, D., \& Robinson, J. (2008). Developing teachers for high-poverty schools: The role of the internship experience. Urban Education, 68-82.

15. Morgan, G. A., Leech, N. L., Gloeckner, G. W., \& Caplovitz-Barrett, K. (2007). Spss for introductory statistics: Use and interpretation (3rd Edition ed.). Mahwah: Lawrence Erlbaum.

16. National Council for Accreditation of Teacher Education. (2008). Retrieved October 28, 2009, from NCATE: http://www.ncate.org/public/glossary.asp?ch=4\#P

17. NCATE. (n.d.). Retrieved November 28, 2009, from National Council for Accreditation of Teacher Education: http://www.ncate.org/public/standards.asp

18. NCATE Standards. (2008). Retrieved March 2010, from National Council for Accreditation of Teacher Education: http://www.ncate.org/public/glossary.asp?ch=155

19. NEA. (2010). Retrieved August 2010, from National Education Association: http://www.nea.org/home/29733.htm

20. Parkison, P. T. (2008). Field placement treatments: A comparative study. The Teacher Educator, 29-45.

21. Peske, H. G., \& Haycock, K. (2006). Teaching inequality: How poor and minority students are shortchanged on teacher quality. The Education Trust.

22. Reynolds, A., Ross, S., \& Rakow, J. (2002). Teacher retention, teaching effectveness, and professional preparation: A comparison of professional develpment school and non-professional develpment school graduates. Teaching and Teacher Education, 289-303.

23. Ross, E. (1986). Becoming a social studies teacher: Teacher education and the development of preservice teacher perspectives. College and University Faculty Association of the National Council for the Social Studies. New York.

24. Sachs, S. (2004). Evlauation of teachers' attributes as predictors of success in uban schools. Journal of Teacher Education, 177-187.

25. Sanders, W. L., \& Rivers, J. C. (1996). Cumulateive and Residual Effects of Teachers on Future Student Academic Achievement. University of Tennessee Value-Added Research and Assessment Center. 
26. Schulte, L., Edick, N., Edwards, S., \& Mackiel, D. (2004). The Development and Validation of the Teacher Dispositions Index. Omaha: University of Nebraska.

27. Sharp, L. K. (2008). Assessing preservice teachers' dispositions: A critical dimension of professional preparation. Childhood Education, 150-153.

28. Singh, D. K. (2006). What do teacher candidates have to say about their clinical experiences? Association of Teacher Educators, (pp. 1-15). Atlanta.

29. Singh, D. K., \& Stoloff, D. L. (2008). Assessment of Teacher Dispositions. College Student Journal.

30. Talbert-Johnson, C. (2006). Preparing Highly Qualified Teacher Candidates for Urban Schools: The Importance of Dispositions. Education and Urban Society, 147-160.

31. Taylor, R., \& Wasicsko, M. (2000). The dispositions to teach. Southern Region Association of Teacher Educators Conference. Lexington.

32. TEAC. (2007). Retrieved November 28, 2009, from Teacher Education Accreditation Council: http://www.teac.org/?page $\mathrm{id}=170$

33. Thompson, S., Ransdell, M., \& Rousseau, C. (2005). Effective teachers in urban school settings: Linking teacher disposition and student performance on standardized tests. Journal of Authentic Learning , 22-36.

34. U.S. Department of Education. (2006). Retrieved October 2009, from National Center for Education Statistics: http://nces.ed.gov/

35. Wayne, A., \& Youngs, P. (2003). Teacher characteristics and student achievement gains: A review. Review of Educational Research.

36. Weglinsky, H. (2002). How schools matter. The link between teacher classroom practices and student academic performance. Education Policy Analysis Archives. 